Article

\title{
An Emulated PV Source Based on an Unilluminated Solar Panel and DC Power Supply
}

\author{
Zhongfu Zhou * and John Macaulay \\ College of Engineering, Swansea University, Bay Campus, Swansea SA1 8EN, UK; 717305@swansea.ac.uk \\ * Correspondence: z.zhou@swansea.ac.uk; Tel.: +44-1792-295232
}

Received: 3 November 2017; Accepted: 1 December 2017; Published: 6 December 2017

\begin{abstract}
This paper provides a review on various PV simulator technologies as well as presents a novel equivalent photovoltaic (PV) source that was constructed by using un-illuminated solar panels and a DC power supply that operates in current source mode. The constructed PV source was used for testing photovoltaic converters and various maximum power point tracking (MPPT) algorithms required for capturing the maximum possible output power. The mathematical model and electrical characteristics of the constructed PV source were defined and analyzed in detail in the paper. The constructed PV source has the advantages of high bandwidth over the switching circuit based PV simulators. The constructed PV source has been used for testing various power electronics converters and various control techniques effectively in laboratory environments for researchers and university students.
\end{abstract}

Keywords: PV simulator; unilluminated solar panel; DC power supply; photovoltaic inverters; maximum power point tracking (MPPT)

\section{Introduction}

The demand for solar energy electricity generation system has been continuously increasing due to the improvement of solar panel and power conversion technology, particularly with growing demand for renewable energy across the world. Large amounts of PV electricity are now injected into utility systems through distribution networks. A solar electricity generation system often comprises many PV arrays and PV inverters. A PV generation system could be formed by many parallel and serial connected PV panels to provide sufficient voltage and currents. A PV inverter that is constructed using power semiconductor devices and microcomputer-based control circuit is used in controlling the PV system operation so that it can always operate at its maximum power point (MPP) to capture the maximum possible power under any given solar irradiance. On the other hand, the PV inverters also convert the dc power generated by PV panel to $50 \mathrm{~Hz}$ ac power at an appropriate voltage suitable for grid connection. PV panels are usually designed with a lifetime of 25 years; however, the PV inverter's lifetime is usually less than that due to the failure of its components. Great attention has been paid to the development of advanced PV inverters to achieve higher efficiency, higher reliability, lower cost and advanced control algorithms. Advanced power semiconductor devices, high-quality capacitors, inductors and advanced inverter circuit topologies and control strategies are the keys for high-quality PV inverters. It is imperative to adequately evaluate the inverter's efficiency, reliability and performance to reduce the development period. For the development and experiment test of photovoltaic converters, repeatable test conditions are very often required to justify their control algorithms [1]. It would be very difficult to carry out repeatable tests by using outdoor installed PV panels as the unpredictable atmospheric conditions affect the repeatability of the test conditions and the high system installation and maintenance cost. Today various PV simulators have been developed to replace actual outdoor PV panels for testing PV inverters and control algorithms, some of them have already being commercially available. 
Firstly, this paper reviews various PV simulator techniques, and secondly, it presents a novel equivalent PV source constructed by connecting unilluminated PV panels and external current source. The review of various PV simulator techniques such as their configurations, characteristics, hardware circuits and control algorithms are presented in Section 3. Section 4 presents the mathematical model and electrical characteristics of the constructed PV source. Test results of the constructed PV source with a boost dc/dc converter and MPPT algorithms are presented in Sections 5 and 6 presents the conclusion.

\section{Mathematical Model of Solar Panels}

The equivalent lumped circuit model of solar cells has been widely used for the performance simulation and prediction for designing, manufacturing and evaluation of PV systems. There are two main models for PV cells, the first one is a single-diode model based on the modified shocked diode equation incorporating a diode quality factor to account for the effect of recombination in space-charge region [2]. Figure 1 shows a single-diode solar cell model. It is represented by a current source in parallel with a diode and a parallel resistor, as well as a series connected resistor at the output terminal.

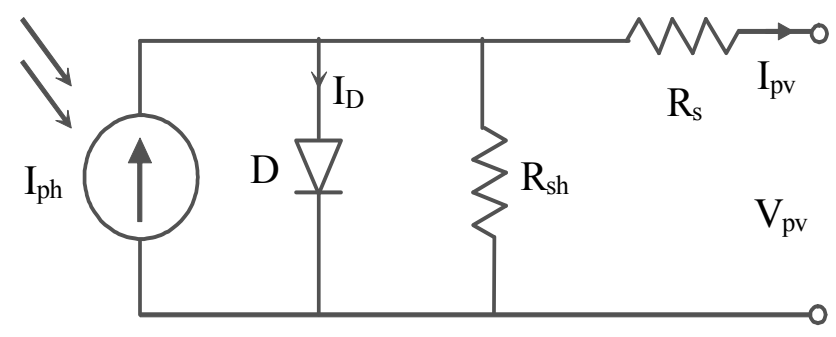

Figure 1. Equivalent circuit of a single-diode solar cell model.

For a solar panel with a number of series-connected PV cells, it is a common practice to assume that the characteristics of the series cells inside the solar panel are nearly identical [3-5]. A PV panel model therefore, is considered as a single cell with some multipliers dependent on the number of series-connected cells in the PV panel. Based on the single-diode model, the I-V characteristic of a PV panel is given by (1):

$$
I_{p v}=I_{p h}-I_{s}\left(e^{\frac{V_{p v}+I_{p v} R_{s}}{n N_{s} V t}}-1\right)-\frac{V_{p v}+I_{p v} R_{s}}{R_{s h}}
$$

where, $I_{p v}$ and $V_{p v}$ are the terminal current and voltage of the PV panel, $I_{p h}$ is the photo current, $I_{s}$ is the dark saturation current, $R_{s}$ and $R_{s h}$ are the series and shunt resistances of the solar panel, $n$ is the diode quality factor, $N_{s}$ is the number of series-connected PV cells in the PV panel, $V_{t}$ is the solar cell thermal voltage defined as $V_{t}=k T / q$, where $\mathrm{k}$ is Boltzmann's constant $(1.38 \times 10-23 \mathrm{~J} / \mathrm{K}), q$ is the elementary charge $(1.6 \times 10-19 \mathrm{C})$, and $T$ is $p-n$ junction temperature in Kelvin.

The second one is the double-diode model, which can simulate the space-charge recombination effect by incorporating a separate current component with its own exponential voltage dependence $[2,6]$.

Figure 2 shows a double-diode solar cell model. It is represented by a current source in parallel with a diode and a parallel resistor, as well as a series connected resistor at the output terminal. 


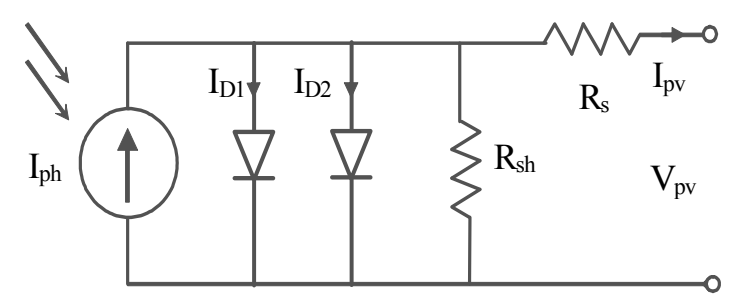

Figure 2. Equivalent circuit of a double-diode solar cell model.

For a solar panel with a number of series-connected PV cells, the I-V characteristic based on the double-diode model is given by (2):

$$
I_{p v}=I_{p h}-I_{s 1}\left(e^{\frac{V_{p v}+I_{p v} R_{s}}{n_{1} N_{s} V_{t}}}-1\right)-I_{s 2}\left(e^{\frac{V_{p v}+I_{p v} R_{s}}{n_{2} N_{s} V_{t}}}-1\right)-\frac{V_{p v}+I_{p v} R_{s}}{R_{s h}}
$$

where, $I_{s 1}$ is the dark saturation current due to diffusion mechanism, $I_{s 2}$ is the dark saturation current due to carrier recombination in space-charge region, $n_{1}$ is the diode quality factor for diffusion current, $n_{2}$ is the diode quality factor for generation-recombination current, the other parameters are the same as in Equation (1) [4].

In practice, the double-diode model can be further simplified by approximating $n_{1}=1$ and $n_{2}=2$ based on Shockley's diffusion theory $[2,6]$. The simplified I-V characteristics for the double-diode model is given in Equation (3):

$$
I_{p v}=I_{p h}-I_{s 1}\left(e^{\frac{V_{p v}+I_{p v} R_{s}}{N_{s} V_{t}}}-1\right)-I_{s 2}\left(e^{\frac{V_{p v}+I_{p v} R_{s}}{2 N_{s} V_{t}}}-1\right)-\frac{V_{p v}+I_{p v} R_{s}}{R_{s h}}
$$

The single-diode model was found not very accurate in describing cell behavior under low illumination conditions $[2,4,6]$. Research shows that estimated series resistance values could be negative using solar module characteristics collected at low solar illuminations [6]. It has been shown that the double-diode model is a more accurate model in presenting the solar panel behavior as compared with the single-diode models particularly at low irradiation levels, as it is able to simulate the space-charge recombination effect by incorporating a separate current component with its own exponential voltage dependence [2,4].

Comparing Equation (3) with Equation (2), there are only five unknown parameters $\left(R_{s}, R_{s h}, I_{s 1}\right.$, $I_{s 2}$, and $\left.I_{p h}\right)$ in Equation (3) which need to be determined based on the available data provided from PV panel's datasheets. Details of the determination of the five parameters were described in [4].

The short circuit current of the solar panel can be calculated by setting $V_{p v}=0$ and neglecting the current through the diode: as expressed in Equation (4):

$$
I_{s c}=\frac{I_{p h}}{\frac{R_{s}}{R_{s h}}+1} \approx I_{p h}
$$

The short-circuit current is approximately equal to the photo- generated current. To achieve the maximum possible output power of a solar panel, the solar panel should be operated at a suitable voltage level at which it can generate its maximum output power. The voltage and current at the MPP can be solved based on Equation (5):

$$
\left.\frac{\mathrm{dP}}{d V}\right|_{V_{M P P}, I_{M P P}}=\left.\frac{d\left(V_{p v} I_{p v}\right)}{d V}\right|_{V_{M P P}, I_{M P P}}=0
$$

where, $V_{M P P}, I_{M P P}$ represents the output voltage and output current of the solar panel respectively [7]. 


\section{Review of PV Simulator Techniques}

To meet the requirement of research on photovoltaic power generation systems, various photovoltaic simulators have been developed over the past decade. Reference [8] presented a simple photovoltaic simulator that was constructed by a dc voltage power supply and a series connected variable resistor as shown in Figure 3. The open circuit voltage of the simulator is determined by setting the dc power supply maximum output voltage. The short-circuit current depends on the power supply voltage setting and the resistance of the variable resistor. The slope of emulated I-V curve was reduced due to the series connected resistor as shown in Figure 3. The main disadvantage of this type of PV simulator is the low efficiency (maximum 50\%) due to power loss in the series resistor at the output.

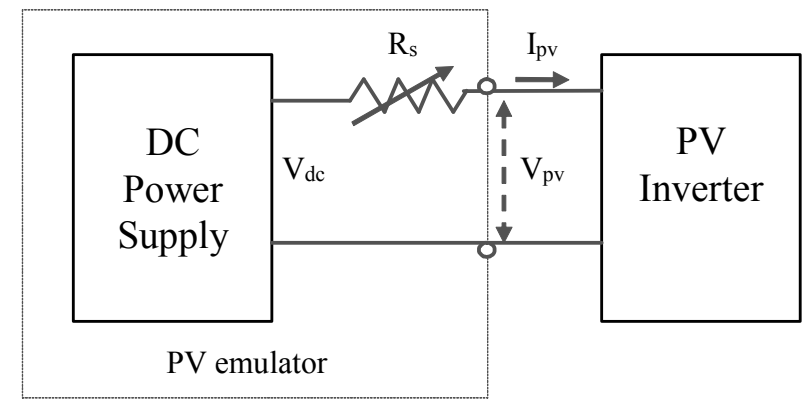

(a)

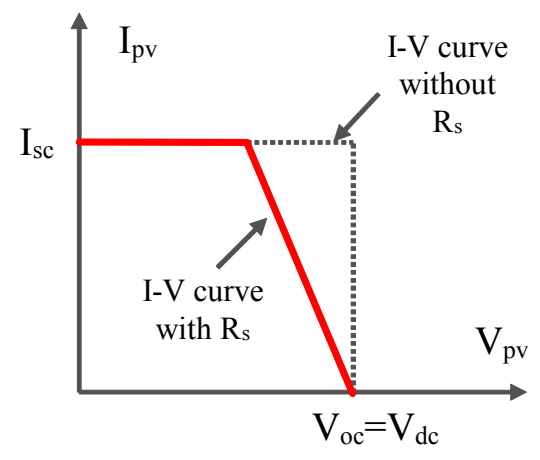

(b)

Figure 3. PV simulator based on DC power supply and a series resistor (a) circuit connection; (b) I-V curves [8].

Research in $[9,10]$ present a solar simulator implemented by amplifying the small current and voltage of a photo-diode using an analog technique. The block diagram of the main experiment circuit is shown in Figure 4.

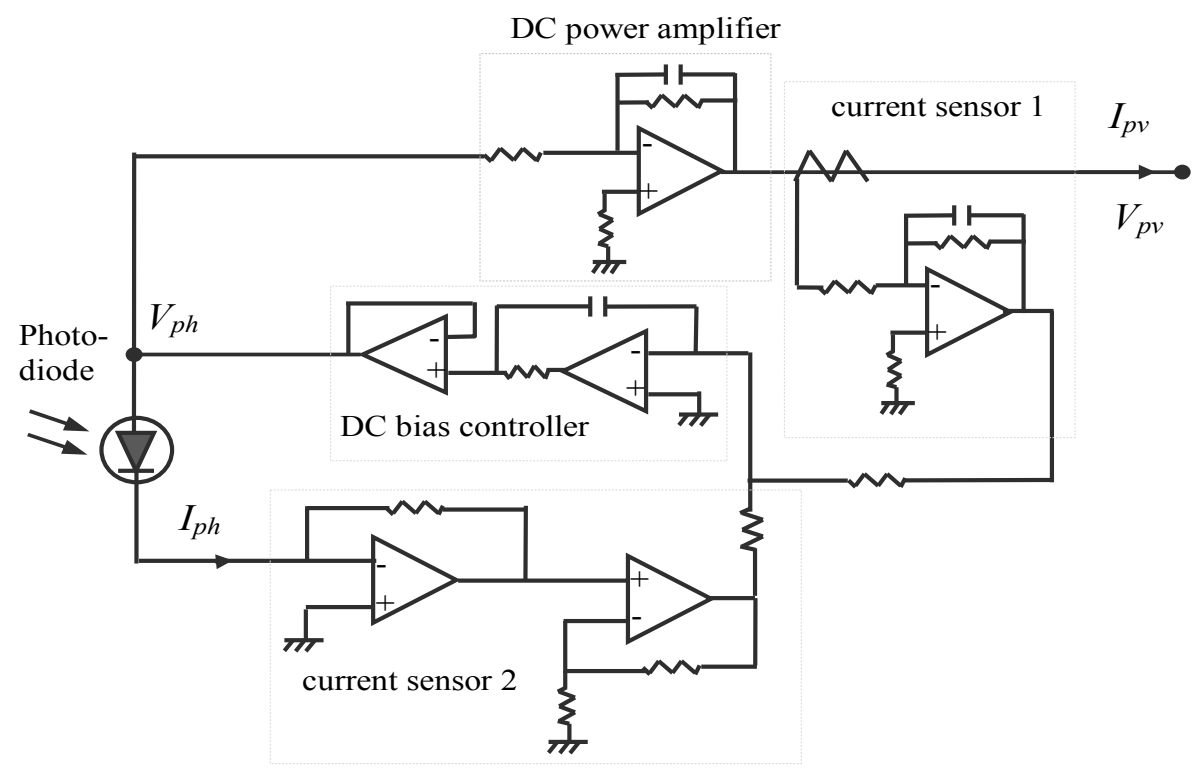

Figure 4. PV simulator based on I-V magnifier of photo-diode $[9,10]$. 
In Figure 4, the voltage of the p-n photo-diode is amplified by the DC power amplifier, the operational point of the photo-sensor is controlled by the DC bias controller based on the feedback signals of the current sensors. It was confirmed that each voltage gain and the current gain of the circuit is independently adjustable, and the circuit amplifies the I-V output of the photo-diode successfully. The output current $I_{p v}$ was controlled by the current feedback control circuit, which was proportional to the photo-diode current $I_{p h}$ Therefore, if the operating point at the output of the PV simulator changes to another point by the changes of the load, the corresponding output current can be amplified and set to a new point on the I-V curve.

The simulator is an amplified photo-diode by using a linear amplifier which was implemented by analog electronics circuit; its output voltage and current are proportional to the photo-diode voltage and current. Thus, the electrical characteristics of the PV simulator are completely dominated by the photo-diode, as a result high bandwidth can be achieved. The results in [9] shows that the open-circuit voltage and short-circuit current of the PV simulator can reach up to $16 \mathrm{~V}$ and $3 \mathrm{~A}$ respectively. The short circuit current of the PV simulator is proportional to the photo-current of the photo-diode depending on the illumination of external light source while the photo-diode voltage will be zero at the condition of short-circuit of the simulator output.

As the circuit was built completely by using analog circuits, it has the advantage of having high bandwidth, hence is suitable for testing PV inverters with high frequency MPPT algorithms. The drawbacks of the analog circuit-based PV simulator are the low efficiency and therefore a large heat sink is required. Nonetheless, the circuit shows good response for more than $1 \mathrm{kHz}$ bandwidth load test, sufficiently fast for evaluating MPPT algorithms and PV inverters. Based on this technique partial shading effect emulation was conducted by using simulator based on the multiple small-scale module units as discussed in reference [11]. Based on techniques above, research in [12] presented a PV simulator which was constructed by using several series connected solar cells to constitute a mini PV-module to provide the reference signal of the PV simulator as shown in Figure 5. The power amplifier circuit was the same as shown in Figure 4.

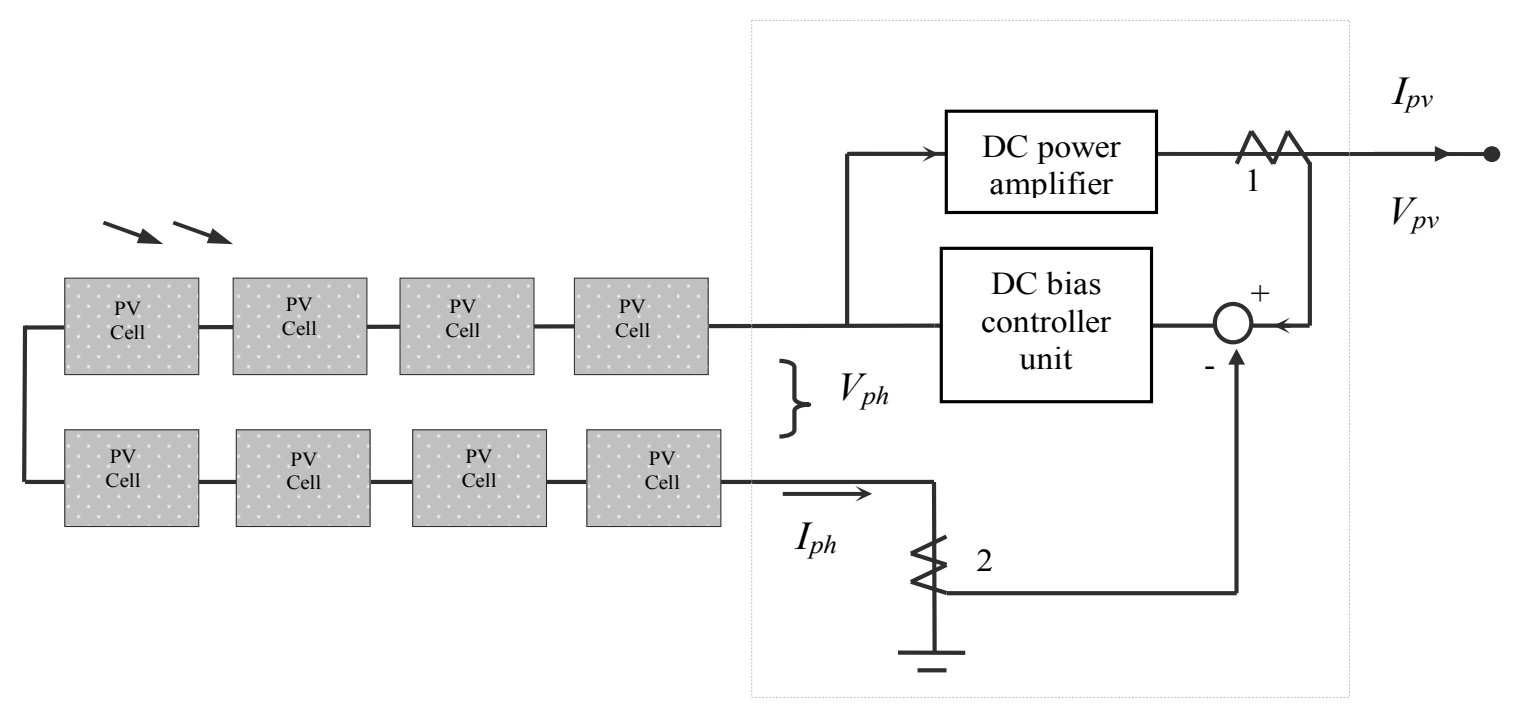

Figure 5. Multiple solar cells based PV simulator.

If the resistances of emulated solar panel are neglected, then the I-V characteristic of the PV simulator is expressed in Equation (6):

$$
V_{p v \_e m u l}=N_{s} V_{T} \ln \left(\frac{I_{p h}-I_{p v \_e m u l}}{I_{0}}+1\right)
$$


Based on Equation (6), an interested low-cost solar PV simulator was implemented in [13] by using discrete operational amplifiers as shown in Figure 6, where voltage $V_{1}$ and $V_{2}$, are the input voltage of the differential amplifier $A_{1}$. These are assumed to be proportional to the photo-current $I_{p h}$ and output current $I_{p v}$ of the PV simulator respectively. Resistances $R_{1}$ to $R_{12}$ are the main parameters of the PV simulator and need to be set carefully. $\mathrm{A}_{3}$ operated as an inverting half-wave rectifier with unity gain which inverts the negative input signal to the amplifier $\mathrm{A}_{4}$, to compensate for the difference between the diode $\mathrm{D}$ thermal voltage and the solar cell thermal voltage as well as amplifying the output. It is a good low-cost solution for implementing PV simulators, however the only disadvantage is that the effect of the series resistance is not considered. When compared against the experimental results for the $12 \mathrm{~W}$ thin film solar cell, there are $5.4 \%$ error for the actual maximum output power and $3.4 \%$ error for the open circuit voltage.

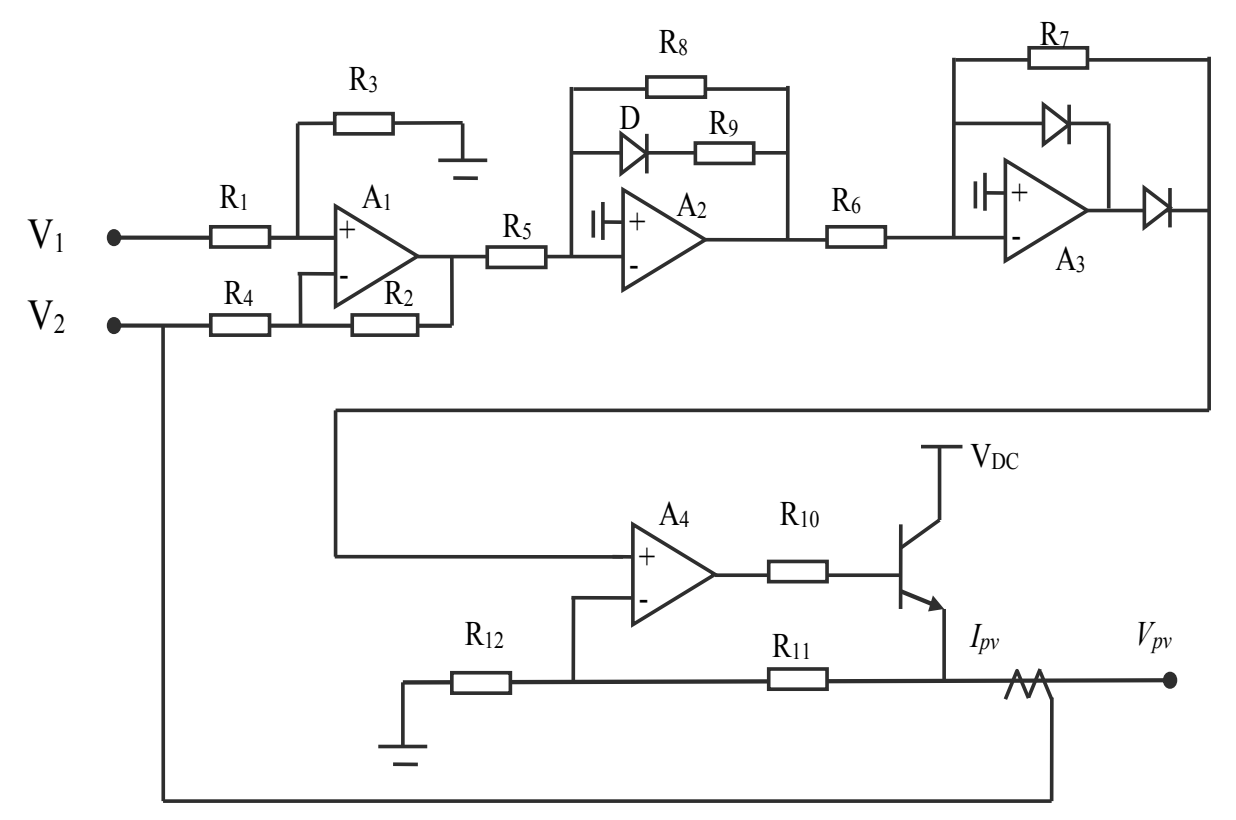

Figure 6. Simplified circuit diagram of the OP-amplifier based PV simulator [13].

Analog technique based PV simulator has the advantage of high bandwidth and it can provide fast response for testing high frequency MPPT algorithms [9-13]. However, this type of PV simulator suffers the disadvantages of low efficiency and large physical size as well as higher manufacturing cost. To overcome the disadvantages of analog technique based PV simulator, switching mode electronic circuits based PV simulators were proposed [14]. Figure 7 shows a general block diagram of switching mode circuit based PV simulator. There are three main parts: the rectifier circuit for supplying dc voltage to the chopper circuit, the switching mode chopper circuit and the feedback control circuits. The dc chopper generates the emulated electrical characteristics of the PV panel/arrays to be emulated. The basic principle of operation is that when the PV simulator is used for testing PV inverters, the terminal voltage $V_{p v}$ is regulated continuously by the connected PV inverter. $V_{p v}$ is also an input signal for the pre-stored PV panel electrical characteristic to find the corresponding reference current of their I-V curves. The chopper circuit current controller controls the output current $I_{p v}$ to track the reference current $I_{p v \_r e f}$.

The basic requirement for the chopper circuit is that it should be able to sweep the entire voltage range of the PV source to be emulated, hence the dc input voltage needs to be higher than the open-circuit voltage of the PV source to be emulated [15]. Figure 8 shows a simplified chopper circuit based PV simulator that was implemented by using buck dc/dc converter [4,14-29]. 


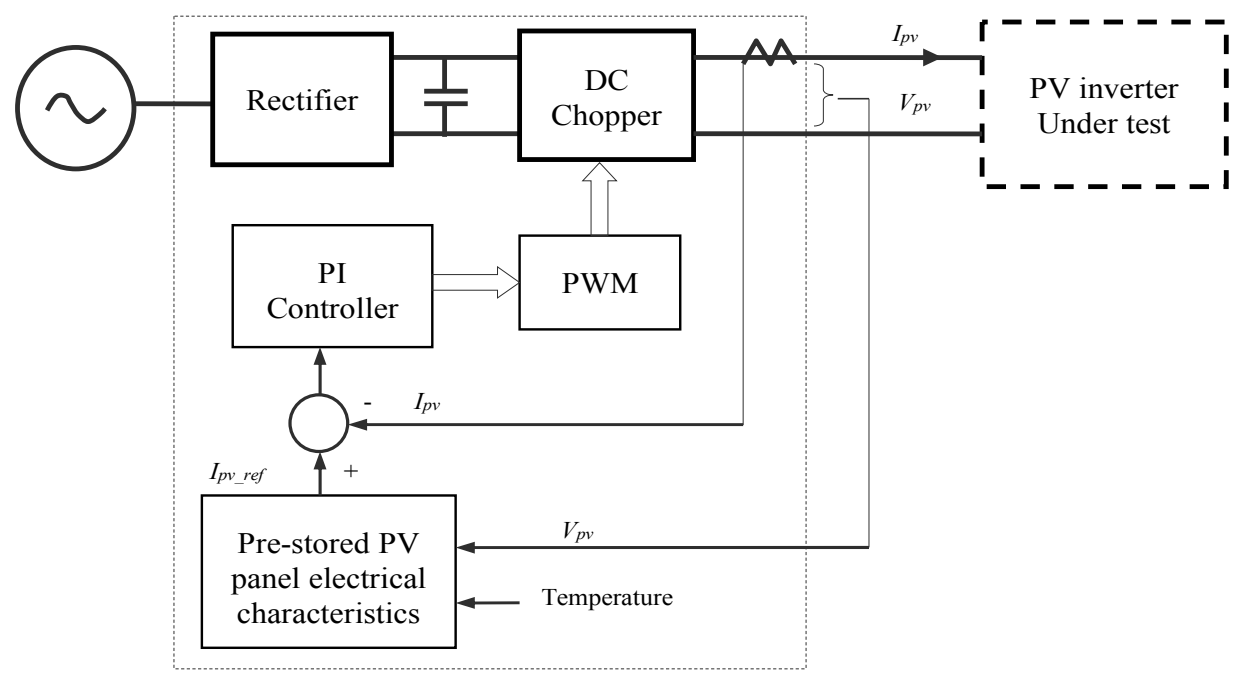

Figure 7. Block diagram of switching mode circuit based PV simulator.

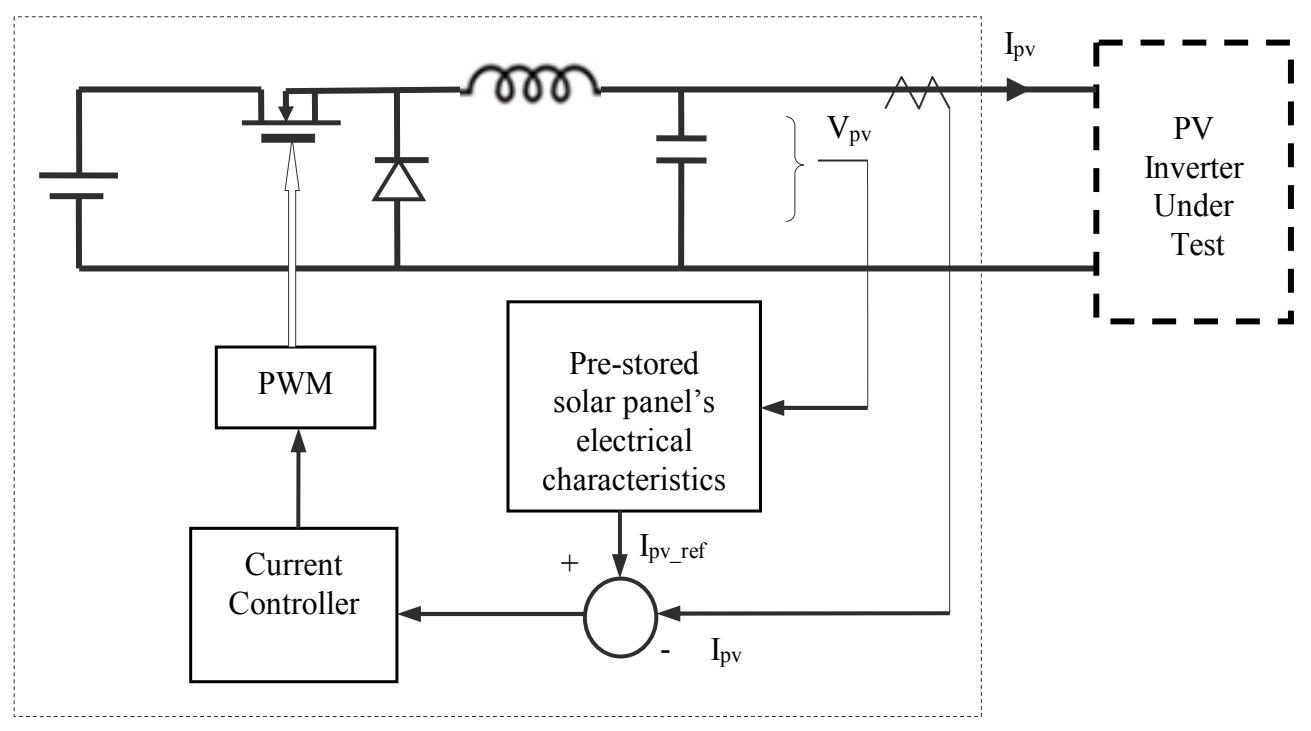

Figure 8. Buck converter circuit based PV simulator.

A topology of a power electronics circuit intended for emulating higher power rating PV system is presented in [18]. The entire voltage range of the PV simulator is between 0 to $650 \mathrm{~V}$, the output current can vary between 0 to $7 \mathrm{~A}$ and the nominal power rating can reach up to $4.4 \mathrm{~kW}$. The circuit topology presented in Figure 9 comprises of a three-phase rectifier, a full-bridge PWM inverter with two high-frequency transformers and two output rectifiers in a series configuration to provide a higher output voltage. The advantages of this topology are the higher power ratings as well as full galvanic isolation [18].

To test PV inverters with high switching frequency, it is necessary that the PV simulator should be designed with high bandwidth to allow actual PV panel/array emulation possible. Therefore, high-speed and sophisticated real-time control circuit is required for PV simulator to provide high crossover frequency so that the PV simulator can act like real PV source. The switching frequency usually is about ten times the crossover frequency for the linear control principles to be effective for the control systems [16,17]. As discussed in [16], a buck dc/dc converter based PV simulator was presented and a switching frequency of $100 \mathrm{kHz}$ was chosen for the buck dc/dc converter to achieve a crossover frequency of $10 \mathrm{kHz}$. 


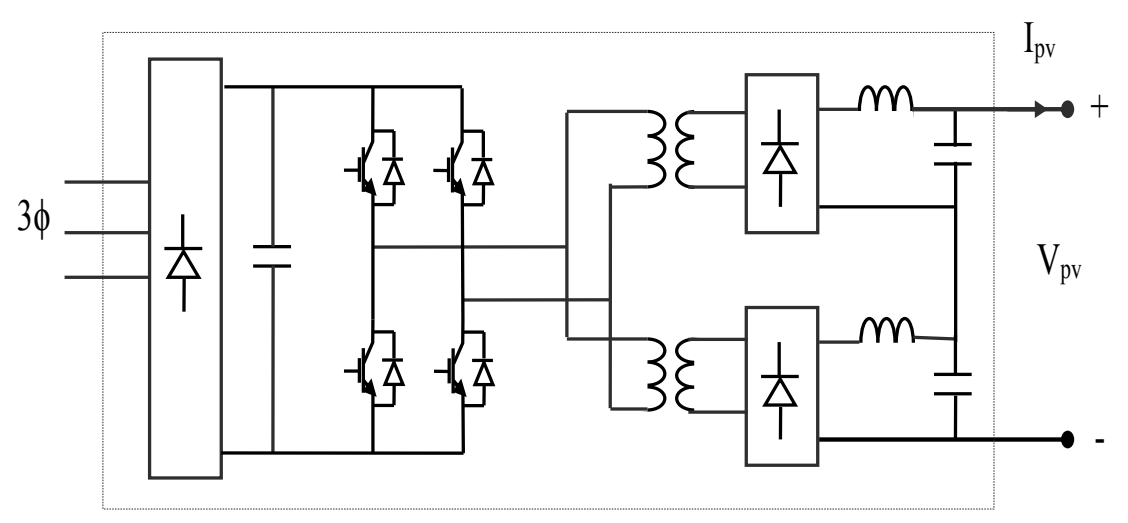

Figure 9. Electrical circuit connection of the high-power PV simulator [18].

In reference [22] a three-phase two-stage high-efficiency PV simulator was presented, in which a three-phase dc-dc interleaved buck converter was employed to emulate the electrical characteristics of a solar panel/array. As interleaved buck converter technique was employed, the output current ripples was reduced to $50 \%$. The experimental results showed that the PV simulator with a bandwidth of $200 \mathrm{~Hz}$ was achieved and able to provide a fast response time to meet various MPPT algorithm requirements.

In addition, a high-efficiency PV simulator based on resonant dc/dc converter was also discussed in [4], in which zero-current switching technique was employed during the switching operation of the converter to improve the efficiency. With the LLC resonant technique applied the output impedance of the converter can be controlled to any value from zero to infinity without any shunt or series connected resistance. Hence the efficiency of the proposed PV emulator was increased significantly.

To emulate a PV panel/array it is essential to have the measured electrical characteristics from the datasheet (such as their I-V curves and temperature effects), which can be prestored in look-up table of the control system of the PV simulator system with reference to [5,30-32] or calculated in real time by using the I-V Equation (1) as discussed in [23,33-35]. The circuit connection for the PV simulator can be seen in Figure 8.

However, the drawback of look-up table based techniques is that the control system will require large memory capacity for storing the large amount of data to represent I-V curves. Due to the large memory storage required it is difficult to implement look-up table for low-cost PV simulators employing simple microcontroller. Nonetheless, the main advantage of implementing look-up table based PV simulator is that it can considerably improve the operational speed of the PV emulator [5]. In contrary, equation based approach requires less memory space, however to accurately model I-V curves higher order equations are needed which can lead to increase of computational time as well as the requirement of high-speed microprocessor.

To overcome the above-mentioned drawbacks of the look-up table and the equation based techniques, an actual solar cell based PV simulator was presented in [22], where, the reference current signal of current controller was generated by a solar cell in real-time by supplying a scaled voltage to the solar cell. The block diagram is shown in Figure 10.

In Figure 10, the analog scaling circuit-2 was designed to output a small voltage $V_{p v \_c e l l}$ in proportional the actual PV terminal voltage, which is then applied to the illuminated PV cell to generate a current $I_{p v_{-} c e l l}$, that was used as the reference current $I_{p v_{-} \text {cell }}$ for the current controller of PV simulator. Comparing to the look-up table method, this method is more accurate, fast and flexible. 


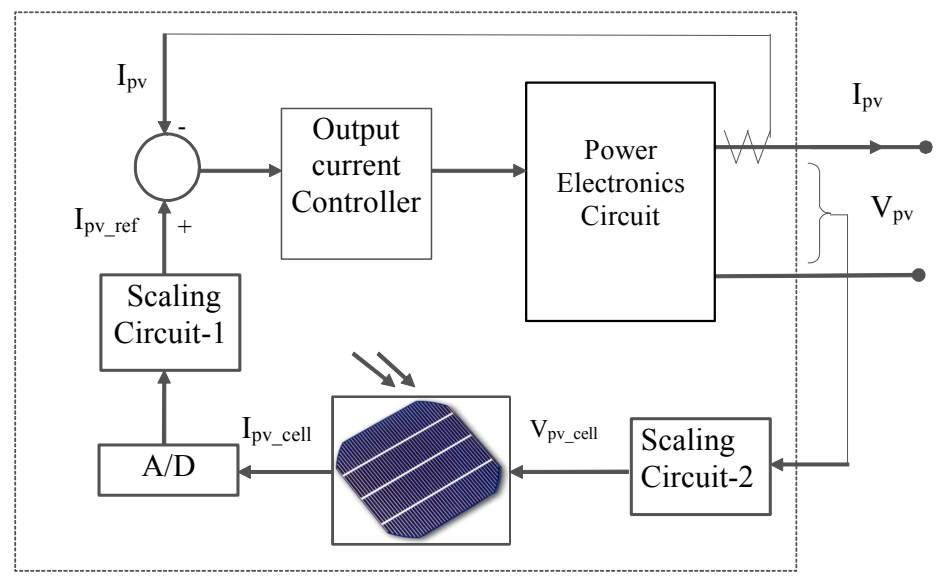

Figure 10. Block diagram of an actual solar cell characteristics based PV simulator [22].

\section{Mathematical Model of the Constructed PV Source}

In this paper, an emulated PV source is constructed by using an un-illuminated PV panel and an external current source for testing PV inverters and MPPT algorithms in the laboratory. The circuit connection of the constructed PV source is shown in Figure 11.

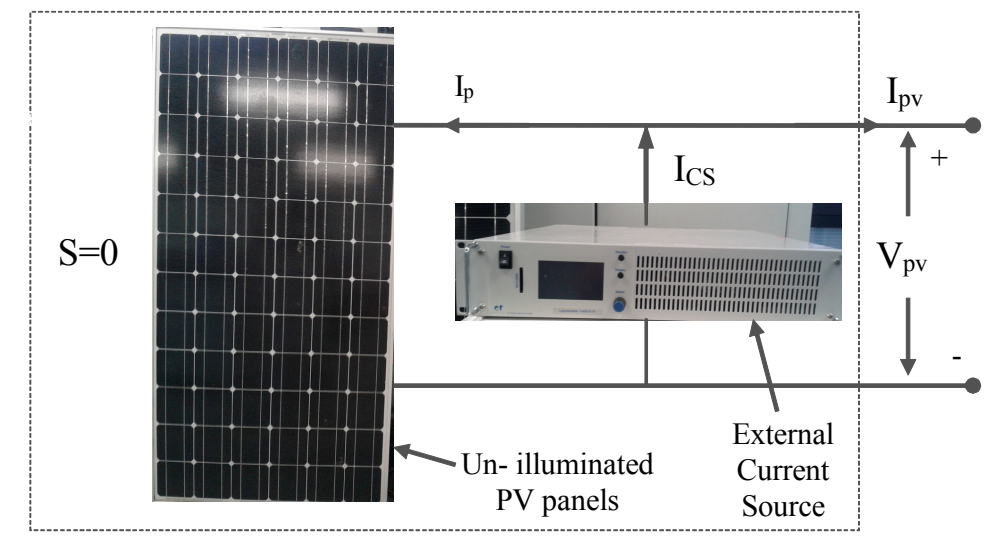

Figure 11. Circuit connection of the emulated PV source.

The equivalent circuit of the constructed emulated PV source is shown in Figure 12, where $I_{\mathcal{C S}}$ represents the current source current generated by the external dc power supply, $D_{b p}$ represents the bypass diode installed in the PV panel. The role the bypass diode is to avoid avalanche breakdown and hot spots during partial shading [4,31,32]. As partial shading was not investigated in the paper so the effect of the diode on the PV source was not considered.

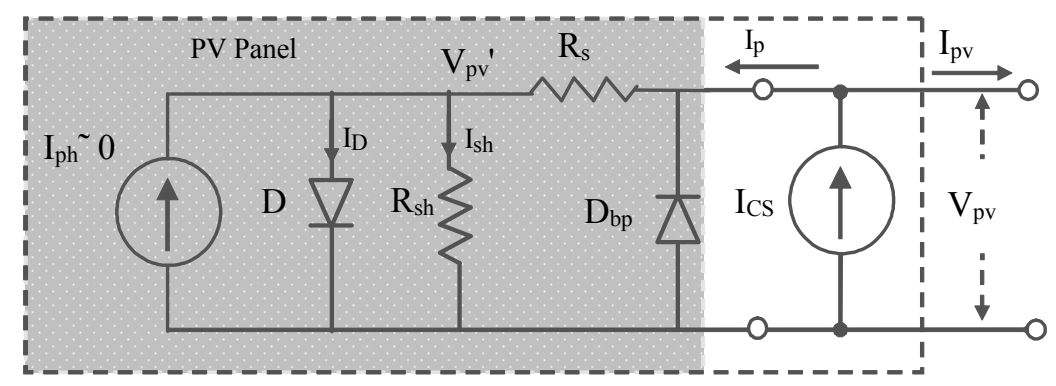

Figure 12. Equivalent circuit of the emulated PV source. 
From Figure 11, the current source current is divided into two parts, one current $I_{p}$ is injected back to the PV panel through the internal series resistance, another current is the output current of the constructed PV source, which is expressed as Equation (7):

$$
I_{p v}=I_{c s}-I_{p}
$$

To simplify the description of I-V relationship of the equivalent PV source, only single-diode model was used to describe the electrical characteristics of the emulated PV source.

Without sunlight illumination the PV panel will generate zero photo-current, i.e., $I_{p h}=0$, the I-V equation of the PV simulator will be expressed by Equation (8):

$$
\begin{gathered}
I_{p v}=I_{c s}-I_{p}=I_{c s}-I_{s}\left(e^{\frac{V_{p v}-I_{p} R_{s}}{N_{s} t_{t}}}-1\right)-I_{s h} \\
V_{p v}=I_{p v} R_{s}+n V_{t} \ln \frac{I_{p}-I_{s h}+I_{s}}{I_{s}} \\
I_{s h}=\frac{V_{p v}-I_{p} R_{s}}{R_{s h}}
\end{gathered}
$$

where, $I_{p v}$ and $V_{p v}$ are the PV simulator's output current and voltage, respectively. The electrical characteristics of the constructed PV source are completely determined by the solar panel's physical properties while the photo-current is provided by the external current source. For a given $I_{c S}$, the current injected into the un-illuminated PV source is represented by Equation (9):

$$
I_{p}=I_{\mathcal{C S}}-I_{P V}
$$

If one assumes that all solar panels have the same leakage current, $I_{s h}$, going through the parallel resistance and the same dark saturation current $I_{s}$, the output voltage $V_{p v}$, of the multi-panel based emulated PV source is expressed by eq. (10)

$$
V_{p v}=\sum_{m=1}^{k} V_{p m}=I_{p}\left(\sum_{k=1}^{M} R_{s k}\right)+V_{t}\left(\sum_{k=1}^{M} N_{s k}\right) \cdot \ln \frac{I_{p}-I_{s h}+I_{s}}{I_{s}}
$$

The proposed emulated PV source can also be constructed using multiple series-connected PV panels to provide a high output voltage and power test conditions. Figure 13 shows the circuit connection of the proposed PV source with multiple series-connected PV panels.

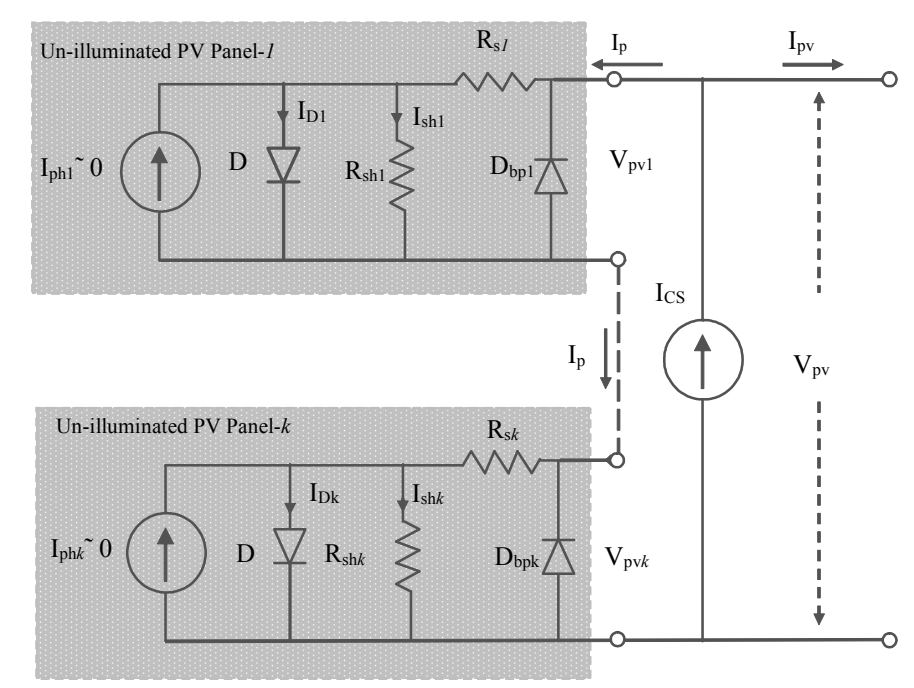

Figure 13. Equivalent circuit of the constructed PV source with multiple un-illuminated solar panels connected in series. 
Starting from the Equation (7), one can derive the current of the multi-panel based PV simulator as:

$$
I_{p v}=I_{\mathcal{~ S S}}-I_{S}\left(e^{\frac{V_{p v}-I_{p} \cdot \sum_{k=1}^{M} R_{s k}}{V_{t} \cdot \sum_{k=1}^{M} N_{s k}}}-1\right)-I_{s h}
$$

where, $R_{s k}$ and $N_{s k}$ are the series resistance and the number of cells connected in series for the k-th PV panel. If all the series connected panels are identical and have the same injected current $I_{p}$, Equation (11) can be further simplified as Equation (12):

$$
I_{p v}=I_{\mathcal{~ S S}}-I_{S}\left(e^{\frac{V_{p v}-I_{p} \cdot m \cdot R_{s}}{V_{t} \cdot m \cdot N_{S}}}-1\right)-I_{s h}
$$

where $m$ represents the number of solar panels connected in series.

\section{Experimental Setup for Testing PV Inverter and MPPT Algorithms}

Experimental setup is shown in Figure 11. The solar panels used in the setup is $175 \mathrm{~W}$ commercial PV panels STP175S-24/Ac from SUNTEC [36]. The parameters of the PV panel under standard test conditions (STC) (i.e., irradiance $1000 \mathrm{~W} / \mathrm{m}^{2}$, module temperature $25^{\circ} \mathrm{C}, \mathrm{AM}=1.5$ ), are given in Table 1. The details of the characteristics of the solar panel can be found in [36].

Table 1. The parameters of the PV panel STP175S-24/Ac at STC [36].

\begin{tabular}{cc}
\hline Rated Maximum Power & $\mathbf{1 7 5}$ Watts \\
\hline Current at the maximum power point & $4.95 \mathrm{Amp}$ \\
Voltage at the maximum power point & $35.2 \mathrm{Volts}$ \\
Short circuit current & $5.2 \mathrm{Amp}$ \\
Open circuit voltage & $44.2 \mathrm{Volts}$ \\
Normal operating cell temperature & $50^{\circ} \mathrm{C}$ \\
\hline
\end{tabular}

A 1800 W DC power supply is connected in parallel with the solar panel. The photocurrent of the PV panel in an indoor environment is very low and is assumed as zero. The dc power supply is operated in a current source mode. Three different configurations of the proposed PV source were constructed and tested with single solar panel test, two solar panels in series connection test as well as three solar panels in series connection test. Figure 14 shows measured electrical characteristics of the proposed emulated PV source with single solar panel at different excitement currents.

Figure 15 shows the electrical characteristic comparison of the constructed PV source with an excitement current $I_{C S}=5.20$ A (corresponding to $1000 \mathrm{~W} / \mathrm{m}^{2}$ at $25^{\circ} \mathrm{C} \mathrm{STC}$ ). There is a small shift for the I-V and P-V curves between the constructed PV source and the actual solar panel when compared (see the datasheet given in [36]). The shift point starts after the point of $\left(V_{p v}=30 \mathrm{~V}, I_{p v}=5.187 \mathrm{~A}\right)$, before the maximum power point (MPP), at which the emulated PV source output current starts reducing rapidly. From Equation (9) the current injected into the solar panel increases with the drop of the output current from the emulated PV source. The difference is approximately determined by the product of the solar panel's series resistance and the current injected into the solar panel from the external current source, i.e., $\Delta V=I_{p} \times R_{s}$ as shown in Figure 11 .

At the point of the open circuit voltage of the emulated PV source, all the current from the external current source is injected into the solar panel, this will generate the maximum voltage shift and the maximum voltage difference $\Delta V_{\max }=I_{\mathcal{C S}} \times R_{S}$. The series resistance of the actual solar panel can also be estimated by: $R_{s}=\Delta V_{\max } / I_{c S}$ In Figure 14, for $I_{\mathcal{~ S S}}=5.20 \mathrm{~A} V_{\text {pv_emul_open }}$ is $46.26 \mathrm{~V}$ and open circuit voltage of the actual solar panel at STC condition: $V_{p v \_a c t u a l}$ open is around $44.2 \mathrm{~V}$. Therefore, the series resistance of the actual PV panel is estimated to be $0.39 \Omega$. 


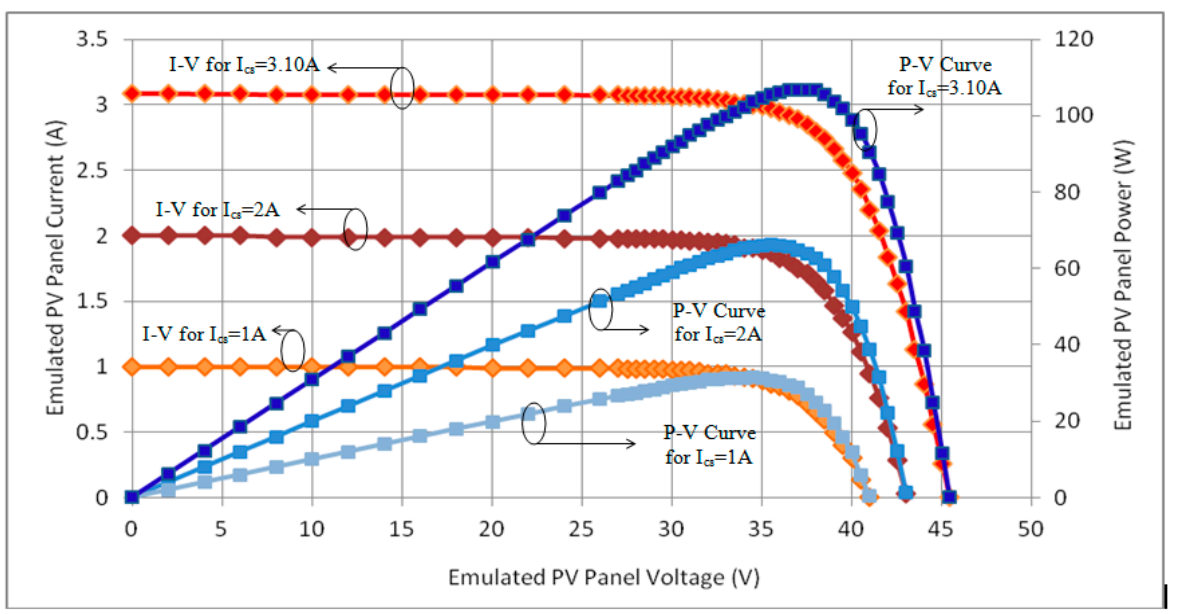

Figure 14. Measured electrical characteristics of the constructed PV source based on single solar panel at different excitement currents.

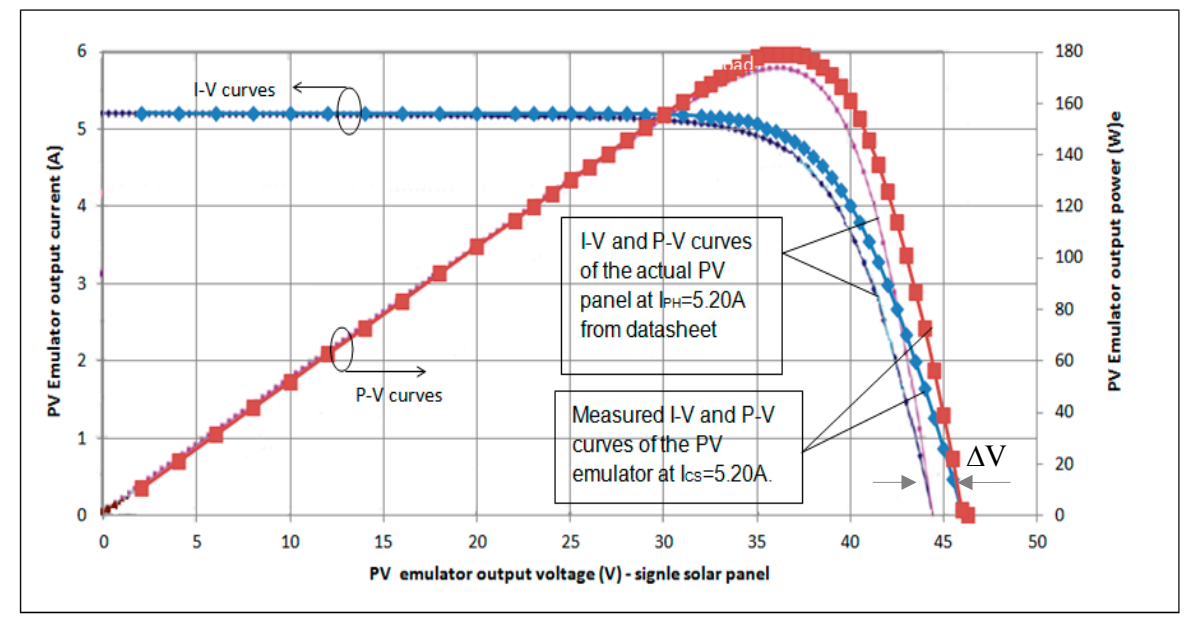

Figure 15. Comparison of the electrical characteristic between the emulated PV source at $I_{\mathcal{C S}}=5.20 \mathrm{~A}$ and the actual solar panel at STC $\left(1000 \mathrm{~W} / \mathrm{m}^{2}, 25^{\circ} \mathrm{C}\right)$.

Figure 16 shows the characteristic per-unit curves of the actual PV panel (Suntech power STP175s-24) [36] at irradiance of $600 \mathrm{~W} / \mathrm{m}^{2}$ (simulated based on the model given in [37]). Figure 17 shows the characteristic per-unit curves of the emulated PV source at 3.14 A excitement current from the external current source, which is equivalent to the short-circuit of the actual PV panel at irradiation of $600 \mathrm{~W} / \mathrm{m}^{2}$.

In Figures 16 and 17 all the curves are presented in per unit, respectively. The base value of the current and voltage are the corresponding current and voltage at the maximum power point (MPP) at irradiance of $600 \mathrm{~W} / \mathrm{m}^{2}$, i.e., $I_{p v \_b a s e}=I_{M P P}=2.81 \mathrm{~A}$ and $V_{p v \_b a s e}=V_{M P P}=35.2 \mathrm{~V}$ respectively. $I_{p v-p . u}=I_{p v} / I_{p v \_b a s e}, V_{p v-p . u}=V_{p v} / V_{p v \_b a s e}$. The per-unit dynamic and static resistance values were drawn based on their maximum values, i.e., $1.8 \mathrm{k} \Omega$ for dynamic resistance, and $950 \Omega$ for static resistance, respectively. Please note that the actual dynamic resistance appeared as negative values across the range of all the operating conditions, for the simplicity of the results presentation, the dynamic resistance values shown in Figures 16 and 17 are their absolute values.

Due to changes in atmospheric conditions the dynamic resistance of the actual PV panel was simulated based on the simulation model provided in [37]. It can be seen from Figure 17 that errors appear with the dynamic resistance, particularly for the values on the left side of the MPP due to the limited resolution of the measurement meter. More so, the curves shown in Figures 16 and 17 are 
very similar except slightly shift on the right-hand side of MPP because of series resistance of the solar panel.

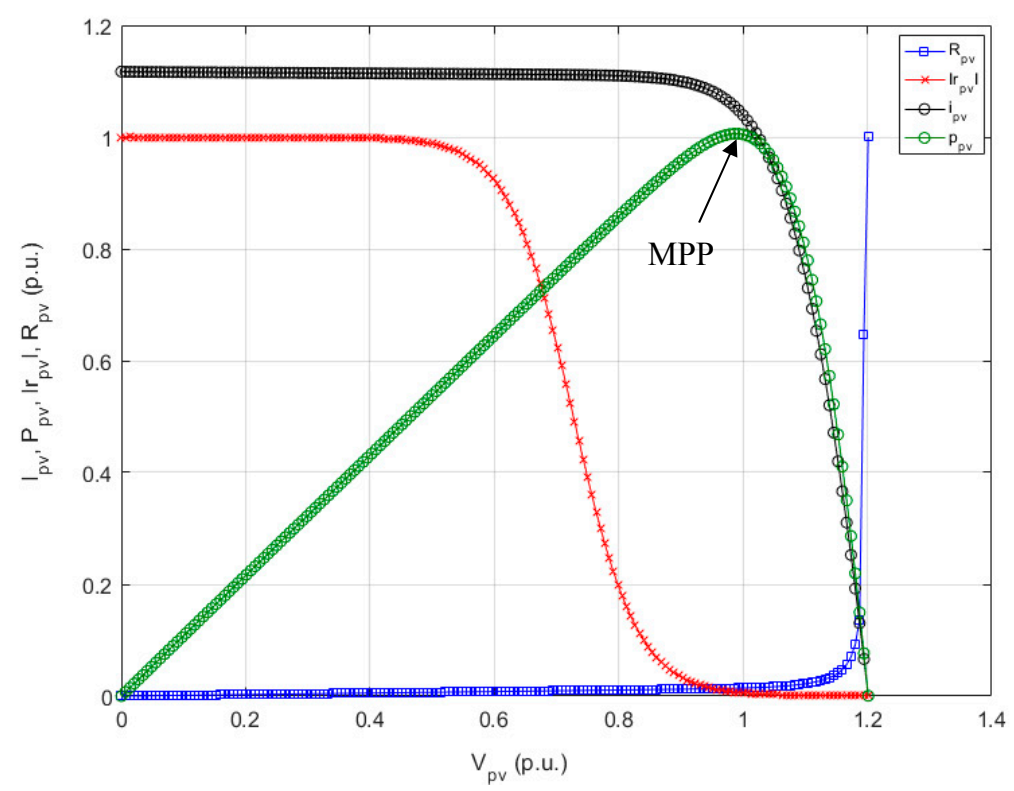

Figure 16. The characteristic per-unit curves of the actual PV panel Suntech power STP175s-24 at irradiance of $600 \mathrm{~W} / \mathrm{m}^{2}$.

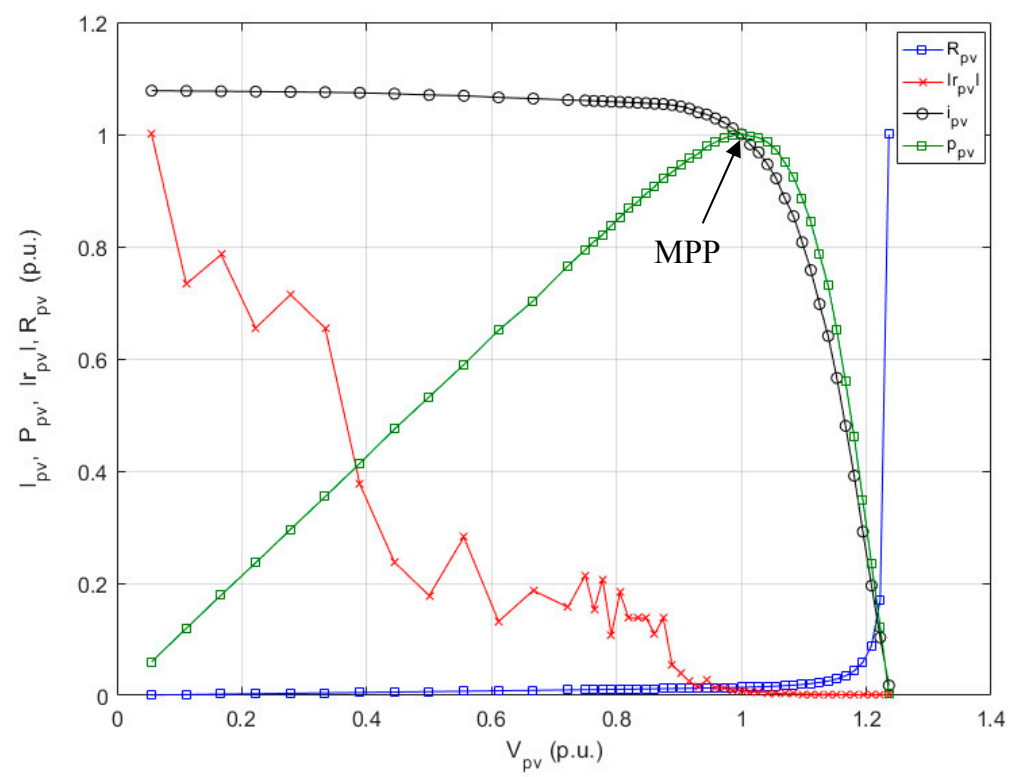

Figure 17. The characteristic per-unit curves of the constructed PV source at excitement current of $I_{C S}=3.14 \mathrm{~A}$.

It is worth mentioning that there are effects of the behavior of the small-signal resistance of the PV generator on the connected power electronics converters as discussed in [38]. It was also noticed earlier that certain commercial emulators may contain resonances, which may lead to unstable operation of the interfacing converter as discussed in [39].

The output power and operational voltage measured at the maximum power point (MPP) versus excitement current $I_{\mathcal{C S}}$, are presented in Figure 18. A linear interpolation method was used to determine the MPP values (power and voltage) for the $I_{c s}$ values between two adjacent measured points. 
The relationship between excitement current $I_{\mathcal{C S}}$, and the power at MPP is shown in Figure 18. One can see that the maximum output power value is proportional to the excitement current (increase in this current corresponds to the increase of the sun irradiance in the outdoor environment). The open-circuit voltage is also affected by the $I_{\mathcal{~ S}}$ and it saturates at higher values of $I_{\mathcal{C S}}$. This variation confirms that MPPT algorithms are essential to control PV inverters to guaranty that a PV source always operates at its maximum power point for any solar irradiance conditions.

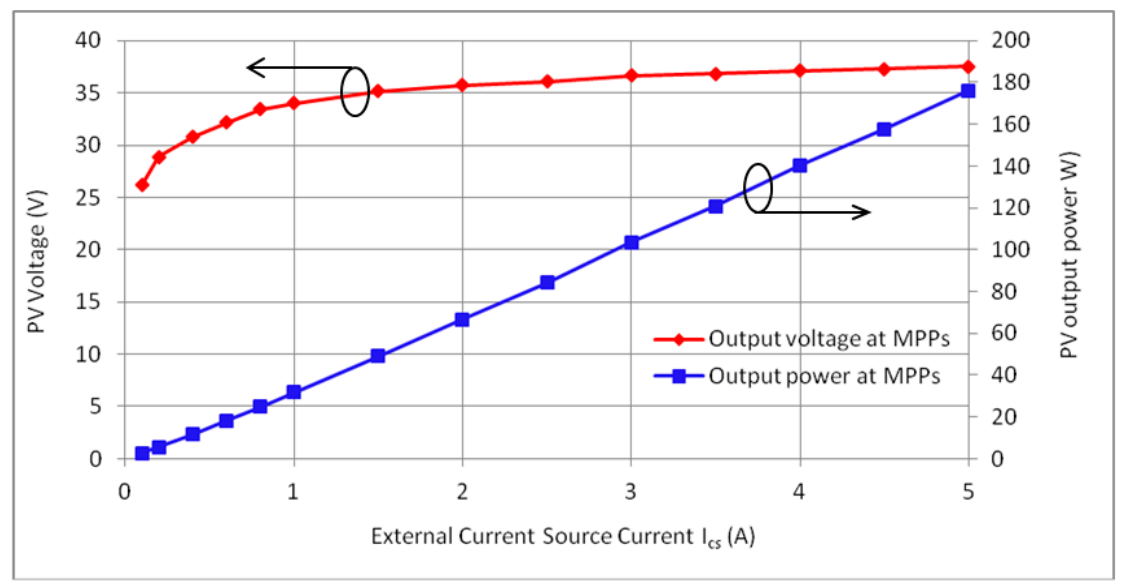

Figure 18. Measured $I_{\mathcal{~ S}}-P_{M M P}$ and $I_{\mathcal{C S}}-V_{M M P}$ curves of the constructed PV source using a single un-illuminated solar panel.

The correlation between the excitement current and the simulated input irradiance on the PV panel STP175S-24/Ac are shown in Table 2.

Table 2. Correlation between the excitement current and the simulated input irradiance on the PV panel STP175S-24/Ac at $25^{\circ} \mathrm{C}$.

\begin{tabular}{cc}
\hline Excitement Current $I_{c s}$ & Simulated Input Solar Irradiation \\
\hline $5.20 \mathrm{Amp}$ & $1000 \mathrm{~W} / \mathrm{m}^{2}$ \\
$4.16 \mathrm{Amp}$ & $800 \mathrm{~W} / \mathrm{m}^{2}$ \\
$3.12 \mathrm{Amp}$ & $600 \mathrm{~W} / \mathrm{m}^{2}$ \\
$2.08 \mathrm{Amp}$ & $400 \mathrm{~W} / \mathrm{m}^{2}$ \\
$1.04 \mathrm{Amp}$ & $200 \mathrm{~W} / \mathrm{m}^{2}$ \\
\hline
\end{tabular}

Nevertheless, it is worth mentioning that in practice apart from the solar irradiance, temperature also affects the performance of the solar panel [16]. Figure 19a shows the simulated electrical characteristics (I-V curves) of the solar panel STP175S-24 with $1000 \mathrm{~W} / \mathrm{m}^{2}$ of solar irradiation at three different temperatures of $25^{\circ} \mathrm{C}, 50{ }^{\circ} \mathrm{C}$ and $75^{\circ} \mathrm{C}$. Figure $19 \mathrm{~b}$ shows simulated electrical characteristics (I-V curves) of the emulated PV source at external excitement current of 5.20 (A). The excitement currents $I_{c S}$. There are slight changes in the excitement current due to temperature variation. Based on Equation (13) at difference temperature and solar irradiance, the external excitement current $I_{C S}$ is calculated as:

$$
I_{\mathcal{C S}}=\left[I_{S C_{-} 25^{\circ} \mathrm{C}}+C_{T}\left(T-T_{r e f}\right)\right] \frac{S}{S_{r e f}}
$$

where, $C_{t}$ is the temperature coefficient of photon current $=1.7 \times 10^{-3}(\mathrm{~A} / \mathrm{K}), T$ is real cell temperature, $S_{r e f}$ is the reference irradiance $=1000\left(\mathrm{~W} / \mathrm{m}^{2}\right), I_{s c}$ is the short circuit current at reference conditions, which is equal to 5.2 (A) for PV panel used. 


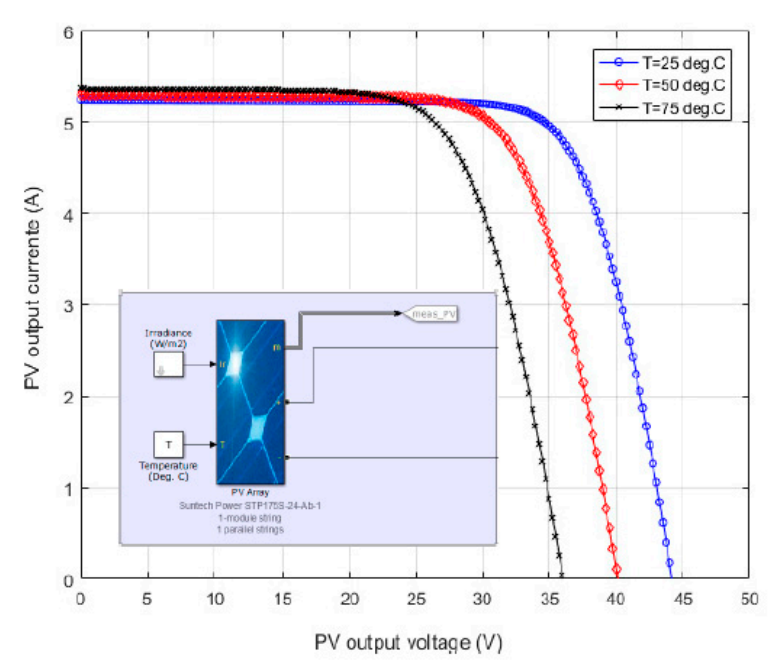

(a)

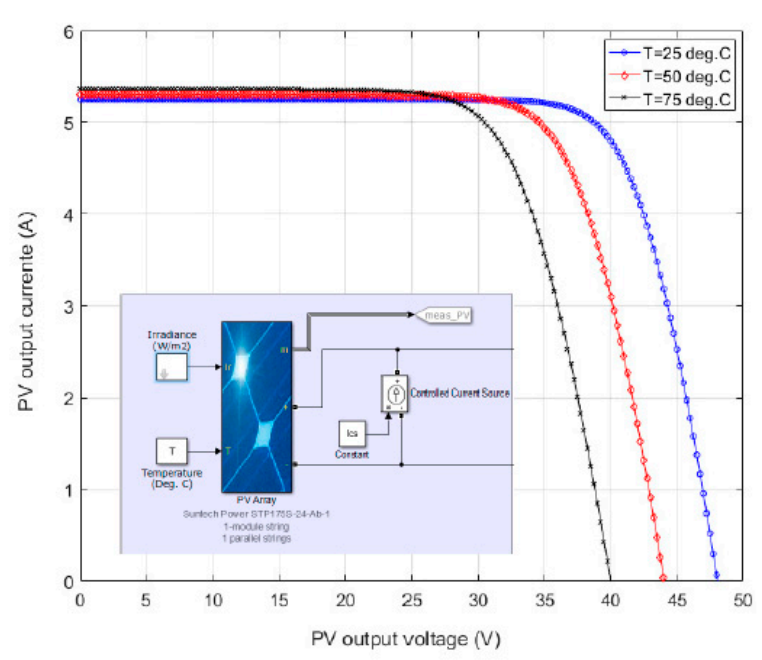

(b)

Figure 19. (a) actual I-V curve temperature variation of PV panel (STP175S-24) at STC. (b) emulated $\mathrm{I}-\mathrm{V}$ curve temperature variation of the emulated PV source.

From Figure 19, the photo-current slightly increase with increase of temperature. However, there is a significantly effect of the temperature on the PV panel's open circuit voltage. From Figure 19a the open circuit voltage reduced from $44.2 \mathrm{~V}$ to 36 when the temperature increases from $25^{\circ} \mathrm{C}$ to $75^{\circ} \mathrm{C}$.

Figures 20 and 21 show the measured P-V and I-V curves of the constructed PV source with two and three PV panels connected in series, respectively. A boost $\mathrm{dc} / \mathrm{dc}$ converter with P\&O MPPT algorithm was developed in the laboratory environment. The proposed PV source with a single PV panel was used in testing the PV inverter and MPPT algorithm. The block diagram and circuit connection of the constructed PV source interfaced with the boost $\mathrm{dc} / \mathrm{dc}$ converter and controller as well as the electronics load is shown in Figure 22.

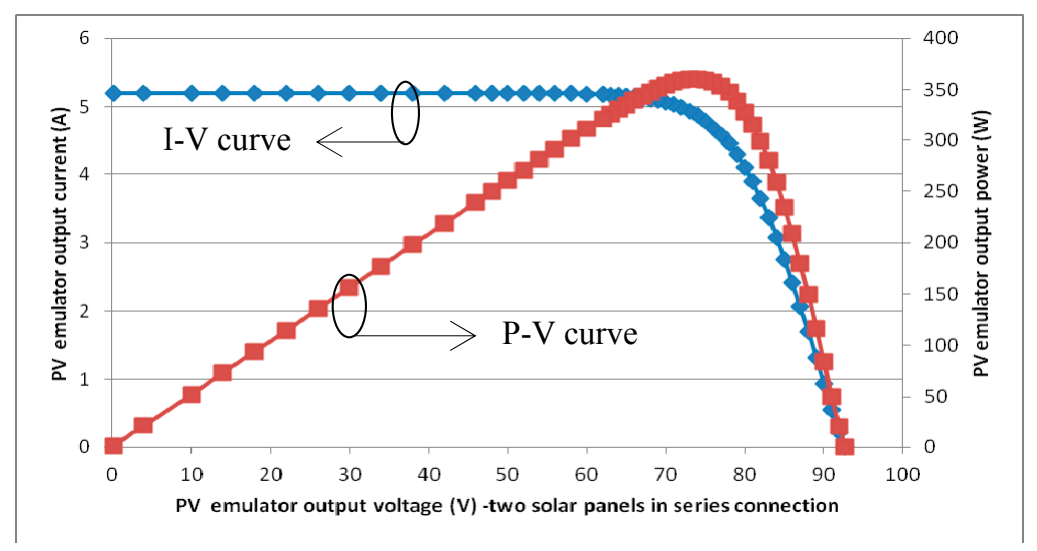

Figure 20. Measured I-V and P-V characteristics of the constructed PV source with two PV panels connected in series. 


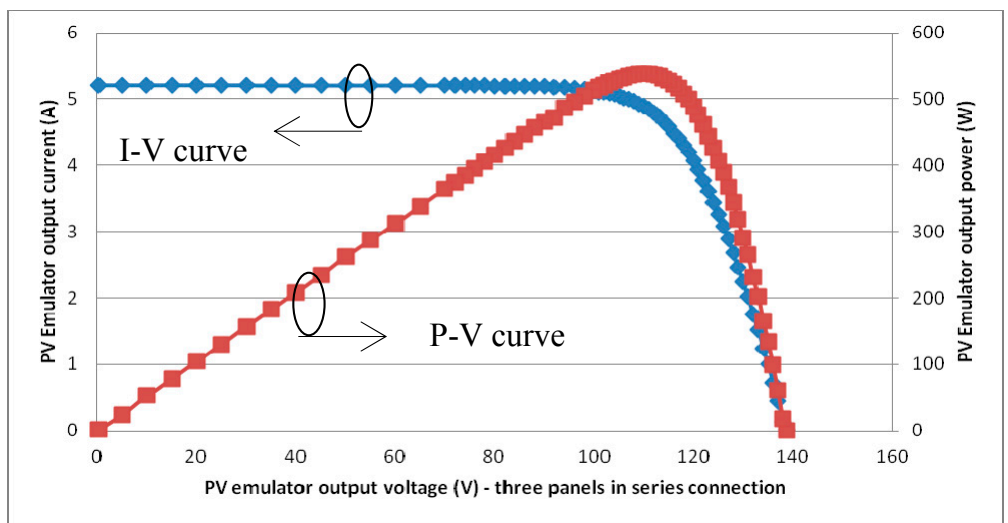

Figure 21. Measured I-V and P-V characteristics of the constructed PV source with three PV panels connected in series.

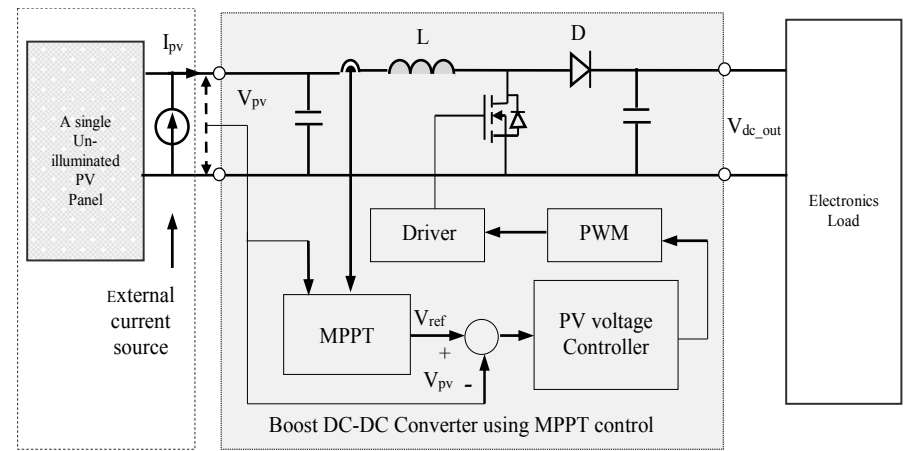

(a) Circuit connection

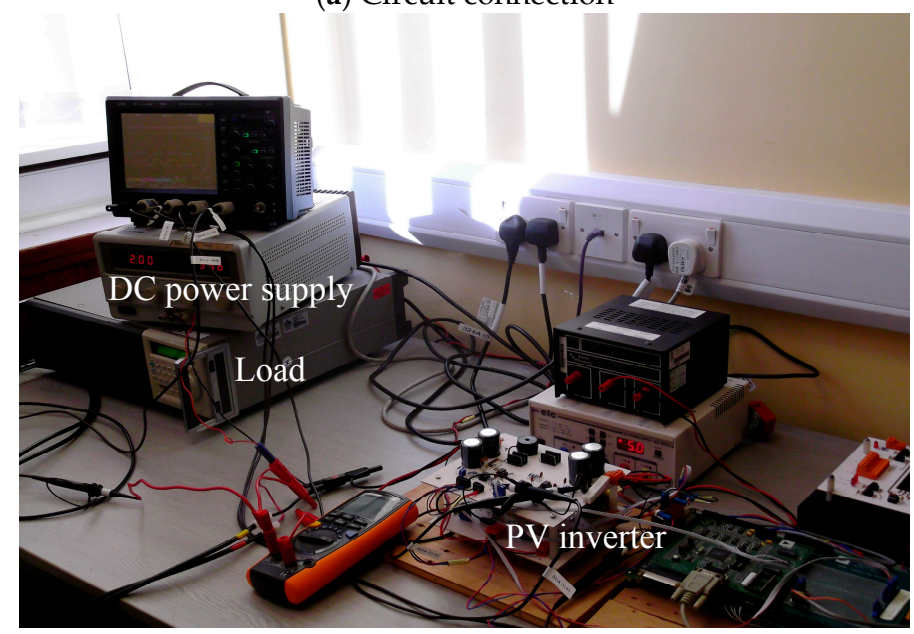

(b) Experiment test system

Figure 22. (a) circuit connection (b) experiment test set-up of the constructed PV source interfaced with power electronics converter and load.

Figure 23 shows the test result of the boost dc/dc converter controlled by a P\&O-MPPT algorithm [40] with a perturbation frequency of $200 \mathrm{~Hz}$ (time step of $5 \mathrm{~ms}$ ) and a perturbation voltage of $0.5 \mathrm{~V}$. The controller was developed using ADMC401 digital signal processor. It was observed during the test that the terminal voltage of the emulated PV source continuously oscillates around the maximum power point due to employment of the MPPT algorithm. The measured mean voltage at MPP is $34.9 \mathrm{~V}$ at excitement current $I_{c s}=1 \mathrm{~A}$, which is corroborated with reference to Figure 14 . Test with varied excitement current was also carried out to simulate PV inverter with the variation of 
solar irradiance. Figure 24 shows how the constructed PV source output voltage and output power changes with the excitement current from the external current source.

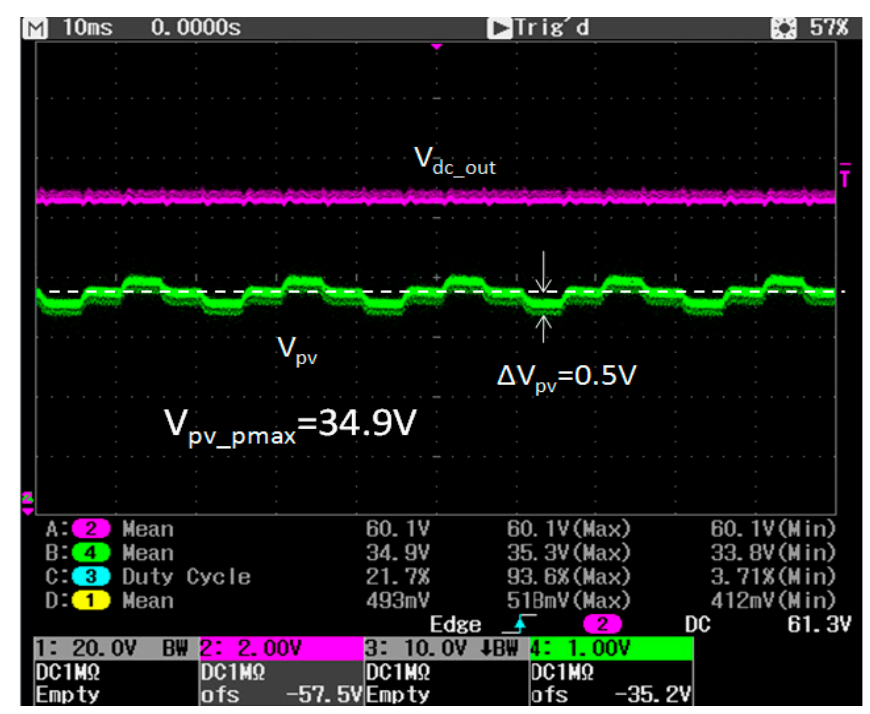

Figure 23. Measured terminal voltage of the constructed PV source for testing a boost dc/dc converter with P\&O MPPT algorithm.

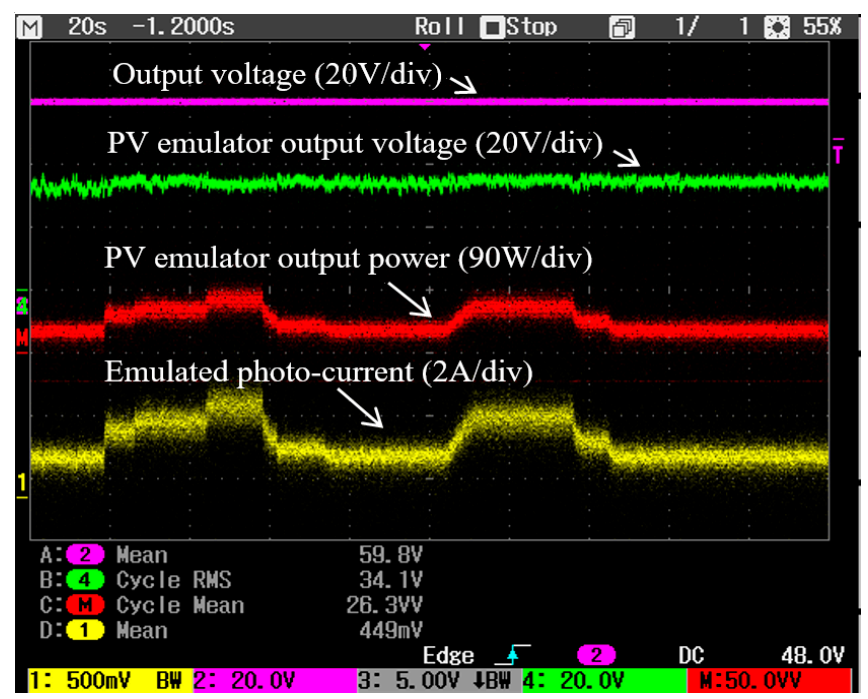

Figure 24. Test with varied external excitement current (in emulating different solar irradiance).

\section{Conclusions}

This manuscript provides a detailed review of various PV simulators previously reported in the literature. This includes the dc power supply and a series connected variable resistor based techniques [8], photodiode current and voltage amplifier based techniques in reference $[9,10]$, actual solar cell amplifier based techniques in reference [11,12], switching-mode power electronic converter based techniques in reference [4,14-29]. Lookup-table and equation based control techniques were discussed in reference [23,30,33-35]. Mathematical models of the constructed PV source with single PV panel and multiple PV panels connected in series were analyzed and presented. The proposed PV source was constructed in a laboratory environment which provides an effective way of testing PV inverters and different MPPT algorithms. The system can provide repeatable test conditions, essential for fast and effective PV inverter development. 
It is important to mention that the proposed emulated PV source was constructed using actual solar panels with an external power supply, the electrical characteristics is mainly determined by the connected solar panel. The proposed PV source has the advantage of high bandwidth which is an essential characteristic for testing high frequency MPPT algorithms. The dc power supply only provides the excitement current to mimic the photocurrent generated at different solar irradiance. The disadvantages are that an actual PV panel will be required to simulate the PV devices, it is also not very convenient to simulate the temperature effect.

Nonetheless, the drawback of the proposed PV source is that the I/V characteristic is slightly different from the one of the unilluminated panel because of the series resistance of the panel. The PV panel must be changed if a different panel need to be simulated, this is because only Iph can be regulated out of the five circuit parameters that define the I-V characteristics of a PV panel $\left(R_{s}, R_{s h}, n, I_{s}\right.$ and $\left.I_{p h}\right)$. Proposed simulator is limited in the sense that it is not convenient in testing temperature effect.

Author Contributions: Zhongfu Zhou conceived this paper and designed the experiments and carried out the experiments. John Macaulay carried out the simulation and measurements. Zhongfu Zhou wrote the paper, both authors revised and approved the final version of the paper.

Conflicts of Interest: The authors declare no conflict of interest.

\section{References}

1. Chua, K.H.; Lim, Y.S.; Taylor, P.; Member, S.; Morris, S.; Member, S.; Wong, J. Energy Storage System for Mitigating Voltage. IEEE Trans. Power Deliv. 2012, 27, 1783-1790. [CrossRef]

2. Chan, D.S.H.; Phang, J.C.H. Analytical Methods for the Extraction of Solar-Cell Single- and Double-Diode Model Parameters from I- V Characteristics. IEEE Trans. Electron Devices 1987, 34, 286-293. [CrossRef]

3. Jiang, T.; Putrus, G.; McDonald, S.; Conti, M.; Li, B.; Johnston, D. Generic Photovoltaic System emulator based on Lambert $\omega$ function. In Proceedings of the 46th International University's Power Engineering Conference, Soest, Germany, 5-8 September 2011.

4. Hejri, M.; Mokhtari, H.; Azizian, M.R.; Ghandhari, M.; Soder, L. On the Parameter Extraction of a Five-Parameter Double-Diode Model of Photovoltaic Cells and Modules. IEEE J. Photovolt. 2014, 4, 915-923. [CrossRef]

5. Gow, J.A.; Manning, C.D. Development of a photovoltaic array model for use in power electronics simulation studies. IEE Proc. Electr. Power Appl. 1999, 146, 193-200. [CrossRef]

6. Chan, D.S.H.; Phang, J.C.H.; Phillips, J.R.; Loong, M.S. A comparison of extracted solar cell parameters from single and double lumped circuit models. In Proceedings of the Technical Digest 1st International Photovoltaic Science and Engineering Conference, Kobe, Japan, 13-16 November 1984; pp. 151-153.

7. Kadri, R.; Andrei, H.; Gaubert, J.; Ivanovici, T.; Champenois, G.; Andrei, P. Modelling of the photovoltaic cell circuit parameters for optimum connection. Energy 2011, 42, 57-67. [CrossRef]

8. Mukerjee, A.K.; Dasgupta, N. DC power supply used as photovoltaic simulator for testing MPPT algorithms. Renew. Energy 2007, 32, 587-592. [CrossRef]

9. Nagayoshi, H.; Orio, S.; Kono, Y.; Nakajima, H. Novel PV array/module simulator circuit. In Proceedings of the 29th IEEE Photovoltaic Specialist Conference, New Orleans, LA, USA, 19-24 May 2002; pp. 1535-1538.

10. Nagayoshi, H. I-V curve simulation by multi-module simulator using I-V magnifier circuit. Sol. Energy Mater. Sol. Cells 2004, 82, 159-167. [CrossRef]

11. Nagayoshi, H.; Atesh, M. Partial shading effect emulation using multi small scale module simulator units. In Proceedings of the Thirty-first IEEE Photovoltaic Specialists Conference, Lake Buena Vista, FL, USA, 3-7 January 2005; pp. 1710-1713.

12. Midtgard, O.-M. A simple photovoltaic simulator for testing of power electronics. In Proceedings of the 2007 European Conference on Power Electronics and Applications, Aalborg, Denmark, 2-5 September 2007; pp. $1-10$.

13. Schofield, D.M.K.; Foster, M.P.; Stone, D.A. Low-cost solar emulator for evaluation maximum power point tracking methods. Electron. Lett. 2011, 47, 208-209. [CrossRef]

14. Rana, A.V. Current Controlled Buck Converter based Photovoltaic Emulato. J. Ind. Intell. Inf. 2013, 1, 91-93. 
15. Zhang, H.; Zhao, Y. Research on a Novel Digital Photovoltaic Array Simulator. In Proceedings of the 2010 International Conference on Intelligent Computation Technology and Automation (ICICTA), Changsha, China, 11-12 May 2010; Volume 2, pp. 1077-1080.

16. González-Medina, R.; Patrao, I.; Garcerá, G.; Figueres, E. A low-cost photovoltaic emulator for static and dynamic evaluation of photovoltaic power converters and facilities. Prog. Photovolt. Res. Appl. 2012, 4, 227-241. [CrossRef]

17. Vorperian, V. Simplified analysis of PWM converters using model of PWM switch-Continuous conduction mode. IEEE Trans. Aerosp. Electron. Syst. 1990, 26, 490-496. [CrossRef]

18. Li, Y.; Lee, T.; Peng, F.Z.; Liu, D. A Hybrid Control Strategy for Photovoltaic Simulator. In Proceedings of the Twenty-Fourth Annual IEEE Applied Power Electronics Conference and Exposition, Washington, DC, USA, 15-19 February 2009; pp. 899-903.

19. Zeng, Q.; Song, P.; Chang, L. A photovoltaic simulator based on DC chopper. In Proceedings of the Canadian Conference on Electrical and Computer Engineering, Winnipeg, MB, Canada, 12-15 May 2002; pp. $257-261$.

20. Di Piazza, M.C.; Vitale, G. Photovoltaic field emulation including dynamic and partial shadow conditions. Appl. Energy 2010, 87, 814-823. [CrossRef]

21. Trapp, J.G.; de Lima, L.P.; Farret, F.A.; Fernandes, F.T.; Balen, G. FC and PV emulation by buck converter based on experimental VxI curves and dynamic response. In Proceedings of the Power Electronics Conference (COBEP), Praiamar, Brazil, 11-15 September 2011; pp. 984-991.

22. Koran, A.; LaBella, T.; Lai, J. High Efficiency Photovoltaic Source Simulator Fast Response Time for Solar Power Conditioning Systems Evaluation. IEEE Trans. Power Electron. 2014, 29, 1285-1297. [CrossRef]

23. Piao, Z.G.; Gong, S.J.; An, Y.H.; Cho, G.B. A study on the PV simulator using equivalent circuit model and look-up table hybrid method. In Proceedings of the 2013 International Conference on Electrical Machines and Systems, Busan, Korea, 26-29 October 2013.

24. Yusivar, F.; Farabi, M.Y.; Suryadiningrat, R.; Ananduta, W.W.; Syaifudin, Y. Buck-Converter Photovoltaic Simulator. Int. J. Power Electron. Drive Syst. 2011, 1, 156-167. [CrossRef]

25. Kondrath, N.; Kazimierczuk, M.K. Comparison of Wide- and High-Frequency Duty-Ratio-to-Inductor-Current Transfer Functions of DC-DC PWM Buck Converter in CCM. IEEE Trans. Ind. Electron. 2012, 59, 641-643. [CrossRef]

26. Koran, A.; Sano, K.; Kim, R.; Lai, J. Design of a Photovoltaic Simulator with a Novel Reference Signal Generator and Two-Stage LC Output Filter. IEEE Trans. Power Electron. 2010, 25, 1331-1338. [CrossRef]

27. Lu, D.D.C.; Nguyen, Q.N. A photovoltaic panel emulator using a buck-boost DC-DC converter and a low cost micro-controller. Sol. Energy 2012, 86, 1477-1480. [CrossRef]

28. Khouzam, K.; Hoffman, K. Real-time simulation of photovoltaic modules. Sol. Energy 1996, 56, 521-526. [CrossRef]

29. Chang, C.; Chang, E.; Cheng, H. A High-Efficiency Solar Array Simulator Implemented by an LLC Resonant DC-DC Converter. IEEE Trans. Power Electron. 2013, 28, 3039-3046. [CrossRef]

30. Park, M.; Yu, I. A novel real-time simulation technique of photovoltaic generation systems using RTDS. IEEE Trans. Energy Convers. 2004, 19, 164-169. [CrossRef]

31. Zheng, H.; Li, S.; Challoo, R.; Proano, J. Shading and bypass diode impacts to energy extraction of PV arrays under different converter configurations. Renew. Energy 2014, 68, 58-66. [CrossRef]

32. Lee, J.E.; Bae, S.; Oh, W.; Park, H.; Kim, S.M.; Lee, D.; Nam, J.; Mo, C.B.; Kim, D.; Yang, J.; et al. Investigation of damage caused by partial shading of CuInxG a(1-x) Se2 photovoltaic modules with bypass diodes. Prog. Photovolt. Res. Appl. 2016, 24, 1035-1043. [CrossRef]

33. Koutroulis, E.; Kalaitzakis, K.; Tzitzilonis, V. Development of an FPGA-based system for real-time simulation of photovoltaic modules. Microelectron. J. 2009, 40, 1094-1102. [CrossRef]

34. Ldloyd, S.; Smith, G.; Infield, D. Design and construction of a modular electronic photovoltaic simulator. In Proceedings of the Eighth International Conference on Power Electronics and Variable Speed Drives, London, UK, 18-19 September 2000; pp. 120-123.

35. Khouzam, K.; Ly, C.; Koh, C.; Ng, P. Simulation and real-time modelling of space photovoltaic systems. In Proceedings of the IEEE WCPEC Conference, Waikoloa, HI, USA, 5-9 December 1994.

36. SUNTECH. PV Module: STP175S-24/Ac, Datasheets. Available online: http://bgsolar.com/_wp/wpcontent/uploads/2011/08/165s-180sAc.pdf (accessed on 2 November 2017).

37. Matlab R2016a. Available online: http:/ / www.mathworks.com (accessed on 2 November 2017). 
38. Suntio, T.; Messo, T.; Aapro, A.; Kivimäki, J.; Kuperman, A. Review of PV generator as an input source for power electronic converters. Energies 2017, 10, 1076. [CrossRef]

39. Nousiainen, L.; Puukko, J.; Maki, A.; Messo, T.; Huusari, J.; Jokipii, J.; Viinamaki, J.; Lobera, D.T.; Valkealahti, S.; Suntio, T. Photovoltaic generator as an input source for power electronic converters. IEEE Trans. Power Electron. 2013, 28, 3028-3038. [CrossRef]

40. Petrone, G.; Spagnuolo, G.; Vitelli, M. A multivariable perturb-and-observe maximum power point tracking technique applied to a single-stage photovoltaic inverter. IEEE Trans. Ind. Electron. 2011, 58, 76-84. [CrossRef] 